\title{
Polytypism of cronstedtite from Chyňava, Czech Republic
}

\author{
Jiří HYBLER ${ }^{1 *}$, Jiří SEJKORA² \\ ${ }^{1}$ Institute of Physics, Academy of Sciences of the Czech Republic, Na Slovance 2, 18221 Prague 8, Czech Republic; hybler@fzu.cz \\ ${ }^{2}$ Department of Mineralogy and Petrology, National Museum, Cirkusová 1740, 19300 Prague 9, Czech Republic \\ * Corresponding author
}

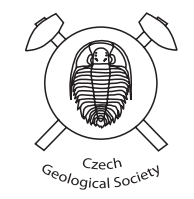

Small druses and isolated crystals of cronstedtite in cavities of a quartz-calcite veinlet were encountered in the borehole drilled near Chyňava (central Bohemia, Czech Republic) in 1943-1944. Single crystals were studied by the X-ray diffraction with aid of the four circle diffractometer with an area detector. The interpretation of precession-like images of reciprocal lattice planes produced by the diffractometer software revealed the polytype $2 H_{1}$ (of the subfamily - Bailey's group D) as the most abundant. It occurs either as pure or mixed crystals with minor to negligible proportion of the $2 \mathrm{H}_{2}$ polytype of the same subfamily. Lattice parameters of both polytypes are: $a=5.4907(3), c=14.1789(9) \AA$, space groups $\mathrm{Pb}_{3} \mathrm{~cm}\left(2 \mathrm{H}_{1}\right)$, and $\mathrm{PG}_{3}\left(2 \mathrm{H}_{2}\right)$. A crystal of the polytype $3 T$ (subfamily A), twinned by reticular merohedry was sparingly found as well. Another unusual mixed crystal of subfamilies $\mathrm{C}+\mathrm{A}$ contained the $1 T$ polytype (subfamily $\mathrm{C}$ ), a disordered portion of the subfamily A except for the apical part of the crystal, and small amount of $3 T$ and possible traces of $6 T_{2}$ polytypes (subfamily A) in the bottom part. Electron probe microanalysis of selected cronstedtite crystals revealed minor amounts of $\mathrm{Cl}$ up to $0.01 \mathrm{apfu}$ (atoms per formula unit), and small amounts of $\mathrm{Mg}(0.13-0.24 \mathrm{apfu})$ regardless of the determined polytype.

Keywords: cronstedtite, polytypes $2 \mathrm{H}_{1}, 2 \mathrm{H}_{2}, 3 \mathrm{~T}, 1 \mathrm{~T}$, twinning

Received: 23 February, 2017; accepted: 17 May, 2017; handling editor: F. Laufek

\section{Introduction}

The rare mineral cronstedtite has been first described from the Vojtěch Mine in Př́bram by Steinmann (1820, 1821). It is named in honor of Swedish chemist and mineralogist Axel Fredrik Cronstedt $(* 23.12 .1722, \dagger 19.8$. 1765), one of the founders of the modern mineralogy. Besides other things, he discovered mineral scheelite, element nickel, and defined zeolites.

At the territory of the today's Czech Republic, cronstedtite has been later described from Kutná Hora (Vrba 1886), Kaňk near Kutná Hora (Novák et al. 1957), Litošice and Sovolusky (Novák and Hoffman 1956; Hybler 1998), Chvaletice (Novák and Jansa 1965; Hybler 1998) and, recently, from Pohled near Havlíčkův Brod (Hybler et al. 2016). The occurrence near the village Chyňava was first mentioned by Fiala (1951), and later described by Fiala and Kouřimský (1980). In Slovakia, cronstedtite was found in Rožňava (Varček et al. 1990) and Nižná Slaná (Hybler et al. 2017).

Cronstedtite typically occurs in low- and mediumtemperature hydrothermal veins together with quartz, calcite, sometimes with siderite, ankerite, rhodochrosite, and/or rhodonite, but always with pyrite - on the surface, in cavities, inter-grown, or embedded in the polycrystalline mass or weathering products (e.g., Hybler et al. 2016, 2017). It has been also found in metamorphic banded iron-formations (Gole 1980a, b; López-García et al. 1992), and in some meteorites - CM chondrites (e.g. Müller et al. 1979; Barber 1981; Burbine and Burns 1994; Browning et al. 1996; Lauretta et al. 2000; Zega and Buseck 2003; Schulte and Schock 2004; Dyl et al. 2010). Pignatelli et al. (2013) synthetized cronstedtite by an iron-clay reaction at $60-90^{\circ} \mathrm{C}$.

Cronstedtite belongs to $1: 1$ phyllosilicates of the serpentine-kaolinite group (Steadman and Nuttall 1964; Steadman 1964). Its structural formula is: $\left(\mathrm{Fe}^{2+}{ }_{3-x} \mathrm{Fe}^{3+}{ }_{x}\right)$ $\left(\mathrm{Si}_{2-x} \mathrm{Fe}^{3+}{ }_{x}\right) \mathrm{O}_{5}(\mathrm{OH})_{4}$, where $x$ is usually in the range of 0.5 to 0.8 . The structure is composed of edge-sharing octahedral and adjacent corner-sharing tetrahedral sheets, forming together 1:1 layer (Bailey 1988). Octahedral positions are occupied by $\mathrm{Fe}^{2+}$ and $\mathrm{Fe}^{3+}$, while in tetrahedral positions is $\mathrm{Si}^{4+}$ partially substituted by $\mathrm{Fe}^{3+}$. The proportion of $\mathrm{Fe}^{3+}$ in octahedra balances the deficiency of charge in tetrahedra. Moreover, a partial substitution of $\mathrm{Fe}^{2+}$ in octahedra for $\mathrm{Mn}^{2+}$ and/or $\mathrm{Mg}^{2+}$ has been reported in some occurrences, e.g. in Pŕíbram (Steinmann 1821; Damour 1860; Janovský 1875; Geiger et al. 1983). A structural analogue of cronstedtite with $\mathrm{Mn}$ and $\mathrm{Mg}$ contents up to 1.86 and $0.54 \mathrm{apfu}$, respectively, was approved as a new distinct mineral species guidottiite (Wahle et al. 2010).

The 1:1 layer silicates including cronstedtite are typical representatives of Order-Disorder structures of layers (OD structures in the following text) with a low degree of desymmetrization (Dornberger-Schiff and Ďurovič 1975a, b; 


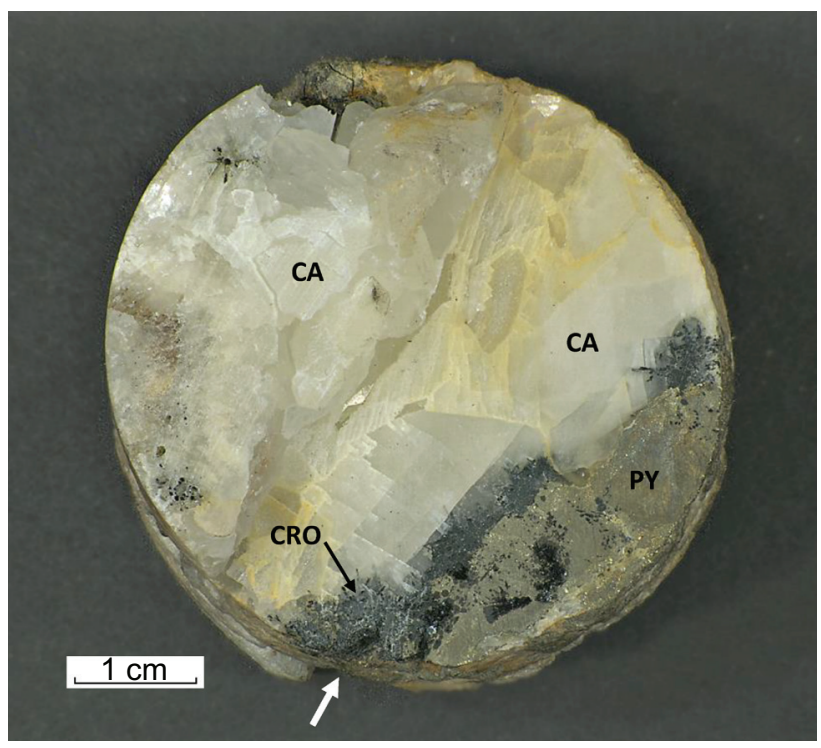

Fig. 1 The drill core intersecting the calcite (CA) veinlet with pyrite (PY) and black cronstedtite (CRO). The small cavity with druses and isolated crystals of cronstedtite is indicated by the white arrow. Some cronstedtite is also embedded in pyrite or calcite.

Durovič 1981, 2004). They belong to the OD family, further subdivided according to shifts and/or rotations of consecutive (identical) layers, into four OD subfamilies, identical with Bailey's $(1969,1988)$ groups: A (polytypes $\left.1 M, 2 M_{1}, 3 \mathrm{~T}, 6 T_{2}\right), \mathrm{B}\left(2 \mathrm{O}, 2 M_{2}, 6 H\right), \mathrm{C}(1 T, 3 R, 2 T), \mathrm{D}$ $\left(2 H_{1}, 6 R, 2 H_{2}\right)$. The stacking rules are represented by following operations: $\pm \mathbf{a}_{\mathbf{i}} / 3$ shifts for subfamily $A, \pm \mathbf{a}_{\mathbf{i}} / 3$ shifts combined with $180^{\circ}$ rotation for subfamily $\mathrm{B}, \pm \mathbf{b} / 3$ or no shift for subfamily $\mathrm{C}, \pm \mathbf{b} / 3$ or no shift combined with $180^{\circ}$ rotation for subfamily $\mathrm{D}$, where $\mathbf{a}_{\mathrm{i}}, \mathbf{b}$ correspond to the vectors of trigonal and orthohexagonal cells, respectively.

Groups and polytypes are identified with aid of characteristic single crystal X-ray diffraction patterns, Selected Area Electron Diffraction (SAED), and Electron Diffraction Tomography (EDT). The X-ray powder diffraction is not reliable in many cases for the polytype determination (Ďurovič 1997).

The current study is intended as a further contribution to knowledge about the polytypism of cronstedtite, mainly from localities in the former Czechoslovakia. Thanks to diffractometers with area detectors, more representative set of specimens might be checked than it was possible previously.

\section{Occurrence}

Cronstedtite was found near the base of the borehole Craelius A-4 drilled in 1943-1944 by the Pražská železářská společnost (Prague Iron Company) $1 \mathrm{~km} \mathrm{~S}$ of the village Chyñava, $7 \mathrm{~km} \mathrm{~N}$ from Beroun, central Bohemia, Czech Republic. The aim of that survey was a

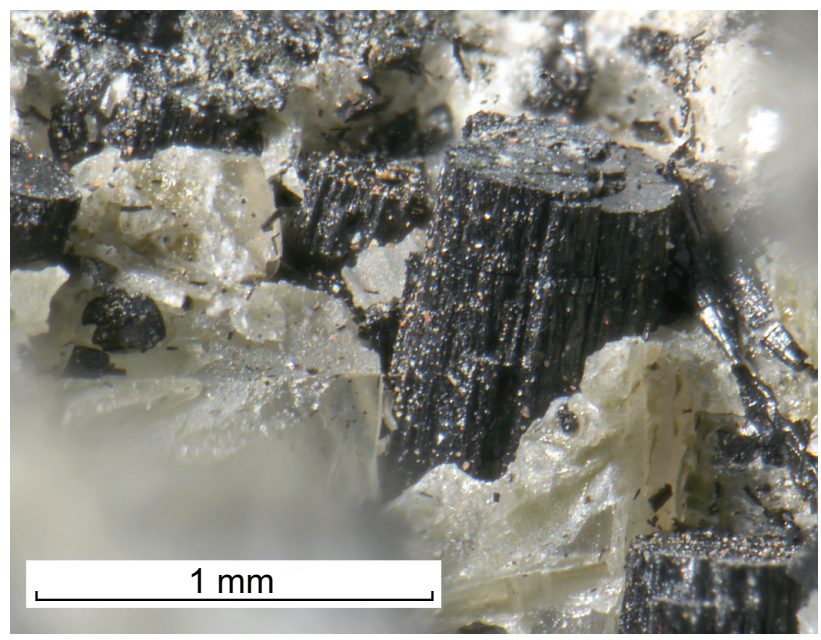

Fig. 2 Typical crystal of cronstedtite in the cavity from Chyňava.

prospecting for Ordovician sedimentary iron ores, excavated in numerous deposits in the region from the Middle Ages to late 1960's. Attempts to localize the borehole more precisely after such a long period of time have been only partially successful. In the original survey report of Měska et al. (1945), no co-ordinates, but only the old (no more valid) cadastral number of the estate where the borehole was located was reported. Comparing the historical cadastral map with the current one, the estate was identified and the approximate position of the borehole was most probably located within $\pm 50 \mathrm{~m}$ around $50^{\circ} 01^{\prime} 3.041^{\prime \prime N}$ and $14^{\circ} 4^{\prime} 25.977^{\prime \prime E}$.

The depth of the drilling was $203.6 \mathrm{~m}$ and the whole profile was described by Měska et al. (1945), later also by Fiala (1951) and Fiala and Kouřimský (1980). At 202 m, in sandy shales of the Třenice Fm. (Tremadocian), a steep veinlet of white calcite, quartz, pyrite and cronstedtite was encountered. Black crystals of cronstedtite occur in fissures and cavities in the veinlet either in druses, or isolated. Some crystals are embedded in accompanying minerals - pyrite, calcite, or quartz. The studied part of the bore-core, $5 \mathrm{~cm}$ in diameter, is stored in the National Museum, Prague (inv. No. 54 444, Figs 1-2).

The cronstedtite occurrence was first briefly mentioned by Fiala (1951, p. 4 and 35). Later Fiala and Kouřimský (1980) reported results of their powder X-ray diffraction and electron microprobe studies. They correctly identified cronstedtite as such, but no attempt to determine polytypes has been done. The aim of the present study is an identification and description of polytypes present in the sample with aid of the single crystal X-ray diffraction.

\section{Experimental}

Crystals for studies were extracted from the veinlet material under the stereomicroscope. Two batches were 
selected: from isolated crystals attached to the inner surface of the veinlet cavity and from the druse of crystals. About 31 specimens altogether were studied.

Crystals are black, with a vitreous luster and an excellent cleavage along basal planes. Predominant forms in the assemblage are columnar, acicular, cylindrical, conical, slim conical, and truncated conical (Fig. 2). Some fragments studied were cleaved plates of larger crystals.

\subsection{Single crystal X-ray diffraction}

Cronstedtite single crystals were glued onto glass wires and mounted on the Oxford Diffraction four-circle (double-wavelength) X-ray diffractometer Gemini A Ultra equipped with the Atlas CCD area detector. Experimental conditions: PANalytical long fine focus tube, graphite monochromator, Mo-enhance fiber optics collimator, $\mathrm{Mo} K_{\alpha}$ radiation, $50 \mathrm{kV}$ and $30 \mathrm{~mA}$. User-defined preexperiments were performed in order to obtain data sets for the lattice parameters and polytype determination in a reasonable time. About 217 frames per one pre-experiment were recorded, covering a sufficiently large area of the reciprocal space with a desired density. The exposure of one frame took 1 second, and a typical run time of one pre-experiment was 20 minutes. A more detailed description of the procedure was given by Hybler et al. (2016). Cleaved fragments of one non-typical crystal (see later) required full experiments, because the images from preexperiments were not clear enough.

The CrysAlis Pro (Rigaku Oxford Diffraction 2015) package was used for the pre-experiment control, and data processing. The lattice parameters were determined automatically during or after the run. The "unwarp" procedure of the CrysAlis Pro package was applied in order to obtain precession-like user-defined sections of the reciprocal space. Although they are sometimes incomplete (with randomly distributed blind areas) and somewhat noisy, they are sufficient for the subfamily and polytype determination in most cases. The images also reveal various defects of crystals, manifested e.g. by diffuse streaking, arc-shaping, and splitting of certain reflections. Second harmonics $(\lambda / 2)$ of strongest reflections (Kirschbaum et al. 1997) are present in some images but did not harm the interpretation.

The OD-subfamilies (Dornberger-Schiff and Durovič 1975a, b) i.e. Bailey's $(1969,1988)$ groups A, B, C, D were determined from the distributions of so-called subfamily reflections along $\overline{2} 1 l, 11 l, \overline{1} 2 l$ rows in reciprocal lattice planes $\overline{2} h h l, h h l, \bar{h} 2 h l$ (hexagonal indices, also in the following throughout the paper, if not stated otherwise). Polytypes were determined from the distribution of characteristic reflections along reciprocal lattice rows $10 l$, $01 l, \overline{1} 1 l$, in planes $h 0 l, 0 k l, \bar{h} h l$ (Mikloš 1975; Duurovič 1981, 1997; Hybler 1998; Weiss and Kužvart 2005).

\subsection{Electron probe microanalysis (EPMA)}

Several crystals or fragments, in that polytypes were already determined, were placed into the resin and polished sections were prepared. The chemical composition was determined using a Cameca SX100 electron microprobe (WDS mode, $15 \mathrm{kV}, 10 \mathrm{nA}$, and $5 \mu \mathrm{m}$ beam diameter) at the Masaryk University in Brno. The following X-ray lines and standards were chosen: $K_{\alpha}$ lines: $\mathrm{Cl}$ (vanadinite), $\mathrm{Fe}$ (almandine), $\mathrm{Mg}$ (pyrope) and $\mathrm{Si}$ (sanidine). Other elements, including $\mathrm{Al}, \mathrm{Ca}, \mathrm{Cr}, \mathrm{Cs}, \mathrm{F}, \mathrm{K}, \mathrm{Mn}, \mathrm{Na}$, $\mathrm{P}, \mathrm{Rb}, \mathrm{S}, \mathrm{Sc}, \mathrm{Ti}, \mathrm{V}$ and $\mathrm{Zn}$ were also sought but they were not found (the respective detection limits are $\sim 0.02-0.10$ wt. \% depending on analytical conditions). Peak counting times were $10-20 \mathrm{~s}$ and the counting times for background were halved. The measured intensities were processed for matrix effects using the " $P A P$ " correction routine (Pouchou and Pichoir 1985). The $\mathrm{H}_{2} \mathrm{O}$ content $(4 \mathrm{OH}+\mathrm{Cl} \mathrm{pfu})$ and $\mathrm{Fe}^{3+} / \mathrm{Fe}^{2+}$ ratio were calculated based on the stoichiometry of general formula $\left(\mathrm{Fe}^{2+}{ }_{3-x} \mathrm{Fe}^{3+}{ }_{x}\right)$ $\left(\mathrm{Si}_{2-x} \mathrm{Fe}_{x}^{3+}\right)_{5}(\mathrm{OH})_{4}$.

\section{Results and discussion}

\subsection{Polytypism and composition of the Chyňava cronstedtite}

The single crystal X-ray studies revealed the polytype $2 H_{1}$ (subfamily D) as the most abundant in the assemblage (Tab. 1). In some crystals it is accompanied by a minor amount, or rather traces of the polytype $2 \mathrm{H}_{2}$. In the majority of reciprocal lattice images the characteristic polytype reflections are diffusely streaked due to partial stacking disorder. Figure 3a represents the plane $h h l$, with $11 l$ reciprocal lattice row characteristic of the $\mathrm{D}$ group. The $h 0 l$ plane of the "pure" $2 H_{1}$ polytype is presented in Fig. 3b. Characteristic reflections 10l, (and 20l, 40l) with $l=2 n+1$ are lacking due to the $P 6_{3} \mathrm{~cm}$ space group extinctions. This crystal (labelled 2-10), is one of three used for data collection for the structure refinement. The $h 0 l$ section (Fig. 3c) represents the $2 H_{1}$ polytype with a very small contribution of $2 \mathrm{H}_{2}$. The weak $l=2 n+1$ reflections are produced by the $2 \mathrm{H}_{2}$ polytype (space group $P 6_{3}$ ), while the $l=2 n$ ones contain contribution of both.

The stacking sequence the $2 H_{1}$ polytype is characterized by regularly alternating $180^{\circ}$ rotations, while in the $2 \mathrm{H}_{2}$ these rotations are combined with $+\mathbf{b} / 3,-\mathbf{b} / 3$ regularly alternating shifts. Both polytypes occur simultaneously in mixed crystals, mostly $2 \mathrm{H}_{2}$ dominant (Kogure et al. 2001). On the contrary, Chyňava crystals are strongly $2 H_{1}$ dominant. In the recently described Pohled occurrence, similar mixed $2 \mathrm{H}_{1}+2 \mathrm{H}_{2}$ crystals were found, some of them moderately $2 \mathrm{H}_{1}$ dominant, others $2 \mathrm{H}_{2}$ dominant (Hybler et al. 2016). 


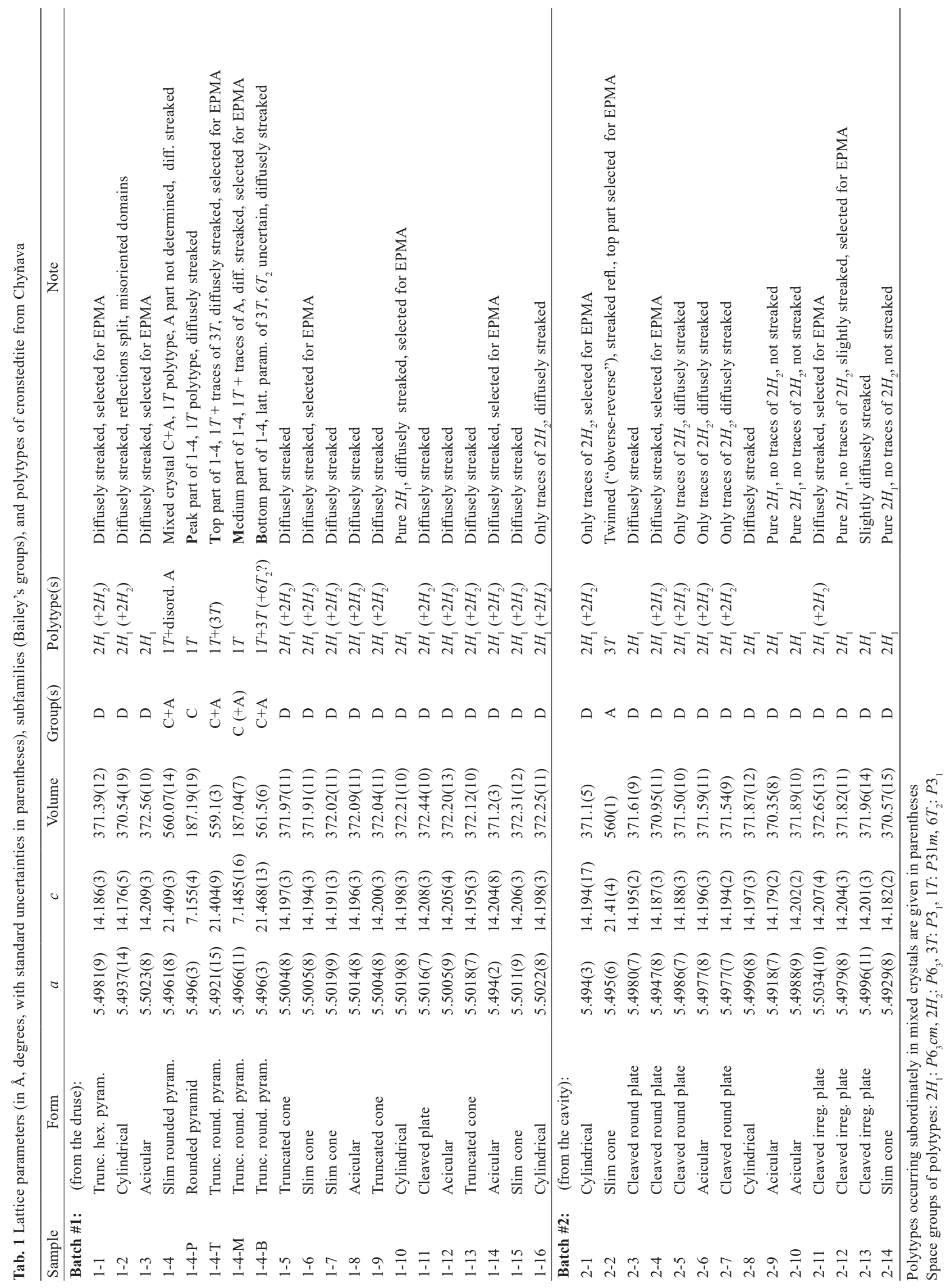




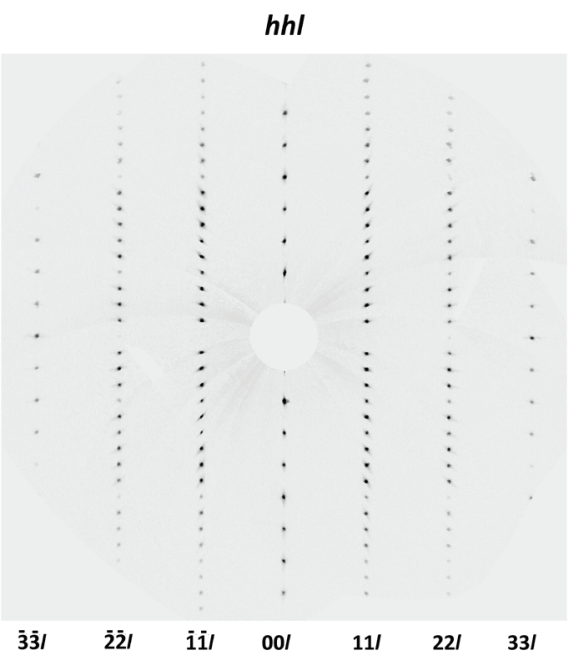

(a) hol

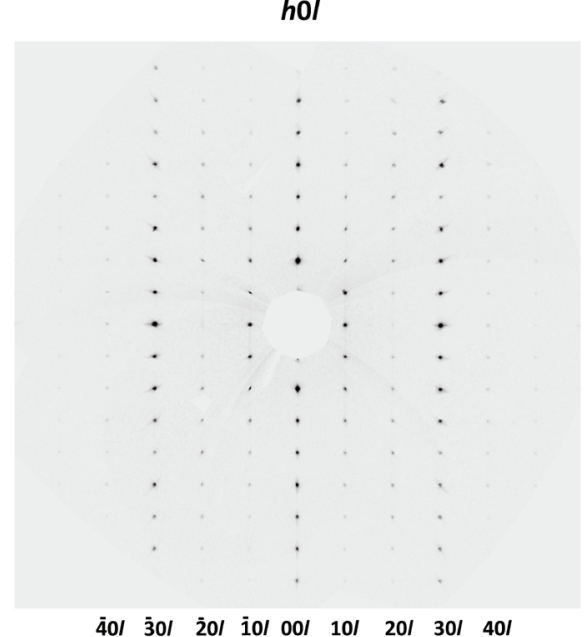

(b)

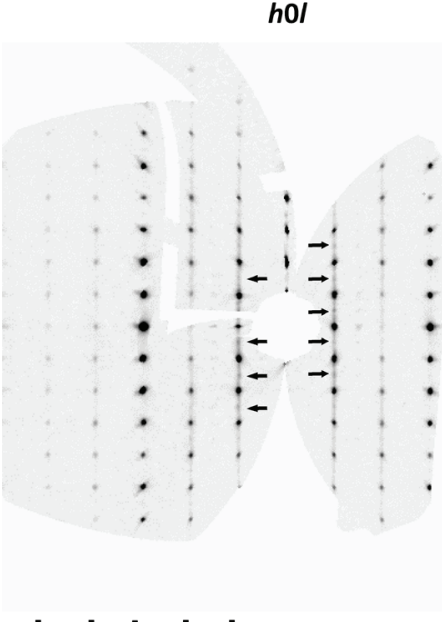

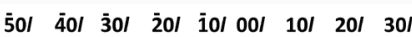

(c)

Fig. 3 Single crystal X-ray patterns. a - The $h h l$ plane characteristic of the subfamily D (full experiment). Note that rows of subfamily reflections $(11 l, 22 l$, etc.) are twice densely occupied as $00 l$ ones because of doubled basic periodicity of polytypes of the subfamily D due to regular alternation of $180^{\circ}$ rotations of $1: 1$ layers. b $-h 0 l$ plane, "pure" $2 H_{1}$ polytype (full experiment). c $-h 0 l$ plane, $2 H_{1}$ polytype with an accessory of $2 \mathrm{H}_{2}$ polytype manifested by weak $l=2 n+110 l$ reflections, indicated by arrows (pre-experiment). Note diffuse streaks along the characteristic reflections due the partial stacking disorder. Weak reflections between $\overline{1} 0 l$ and $\overline{2} 0 l$, as well as between $10 l$ and $20 l$ rows are second harmonics of strong $\overline{3} 0 l$ and $30 l$ reflections, respectively.

Samples of pure $2 H_{1}$ polytype are poorer in $\mathrm{Fe}$ $(x=0.77-0.82)$ than those of $2 H_{1}\left(+2 H_{2}\right)$ polytypes $(x=0.79-0.84)$. Besides the prevailing $\mathrm{Si}$ and $\mathrm{Fe}$, minor amounts of $\mathrm{Cl}$ (up to 0.01 apfu; Fig. 4a) and $\mathrm{Mg}$ (mainly in the range $0.13-0.18$ apfu; Fig. 4b) were detected. The presence of minor $\mathrm{Cl}$ in cronstedtite is already known, e.g. from Pohled (Hybler et al. 2016) or (together with S) from Nižná Slaná (Hybler et al. 2017).

Certain contents of $\mathrm{Mg}$, accompanied also by $\mathrm{Mn}$, have been referred in ancient wet analyses of cronstedtite from Prŕbram (Steinmann 1821; Damour 1860; Janovský 1875). It seems probable that all authors analyzed specimens from the same batch. Contrary to analyses reported,

Tab. 2 Chemical composition of cronstedtite from Chyňava (wt. \% and apfu)

\begin{tabular}{|c|c|c|c|c|c|c|c|c|c|c|c|c|}
\hline \multirow{2}{*}{$\begin{array}{l}\text { Polytype(s) } \\
\text { sample }\end{array}$} & \multicolumn{3}{|c|}{$2 H_{1}$} & \multicolumn{6}{|c|}{$2 H_{1}\left(+2 H_{2}\right)$} & \multirow{2}{*}{$\begin{array}{l}3 T \\
2-2\end{array}$} & \multirow{2}{*}{$\begin{array}{c}1 T+3 T \\
1-4-\mathrm{T}\end{array}$} & \multirow{2}{*}{$\begin{array}{c}1 T \\
1-4-\mathrm{M}\end{array}$} \\
\hline & $1-10$ & $1-3$ & $2-12$ & $1-1$ & $1-14$ & $1-6$ & $2-1$ & $2-11$ & $2-4$ & & & \\
\hline$n$ & 4 & 4 & 5 & 4 & 9 & 4 & 4 & 4 & 5 & 4 & 4 & 4 \\
\hline $\mathrm{FeO}$ & 37.51 & 37.34 & 37.34 & 37.55 & 36.97 & 37.68 & 37.07 & 37.37 & 37.35 & 37.34 & 40.49 & 40.50 \\
\hline $\mathrm{MgO}$ & 1.41 & 1.70 & 1.77 & 1.59 & 1.51 & 1.61 & 1.68 & 1.59 & 1.65 & 2.08 & 2.36 & 2.50 \\
\hline $\mathrm{Fe}_{2} \mathrm{O}_{3}$ & 33.05 & 31.79 & 31.97 & 32.74 & 33.38 & 33.84 & 33.32 & 33.33 & 33.30 & 31.17 & 26.37 & 25.65 \\
\hline $\mathrm{SiO}_{2}$ & 18.17 & 18.52 & 18.57 & 18.41 & 17.92 & 18.36 & 18.15 & 18.24 & 18.29 & 18.98 & 21.62 & 21.84 \\
\hline $\mathrm{Cl}$ & 0.04 & 0.05 & 0.04 & 0.04 & 0.04 & 0.04 & 0.03 & 0.04 & 0.03 & 0.03 & 0.04 & 0.03 \\
\hline $\mathrm{O}=\mathrm{Cl}$ & -0.01 & -0.01 & -0.01 & -0.01 & -0.01 & -0.01 & -0.01 & -0.01 & -0.01 & -0.01 & -0.01 & -0.01 \\
\hline $\mathrm{H}_{2} \mathrm{O}$ & 9.17 & 9.13 & 9.16 & 9.20 & 9.13 & 9.31 & 9.19 & 9.22 & 9.23 & 9.20 & 9.45 & 9.44 \\
\hline total & 99.34 & 98.52 & 98.85 & 99.53 & 98.94 & 100.82 & 99.43 & 99.78 & 99.85 & 98.79 & 100.32 & 99.95 \\
\hline$\overline{\mathrm{Fe}^{2+}}$ & 2.050 & 2.049 & 2.041 & 2.044 & 2.029 & 2.027 & 2.020 & 2.031 & 2.027 & 2.034 & 2.148 & 2.151 \\
\hline $\mathrm{Mg}^{2+}$ & 0.138 & 0.166 & 0.173 & 0.154 & 0.147 & 0.154 & 0.163 & 0.154 & 0.160 & 0.202 & 0.223 & 0.236 \\
\hline $\mathrm{Fe}^{2+}+\mathrm{Mg}^{2+}$ & 2.187 & 2.215 & 2.214 & 2.198 & 2.176 & 2.181 & 2.183 & 2.185 & 2.187 & 2.336 & 2.371 & 2.387 \\
\hline$\overline{\mathrm{Fe}^{3+}}$ & 1.625 & 1.570 & 1.572 & 1.603 & 1.648 & 1.638 & 1.634 & 1.630 & 1.626 & 1.528 & 1.258 & 1.226 \\
\hline $\mathrm{Si}$ & 1.187 & 1.215 & 1.214 & 1.198 & 1.176 & 1.181 & 1.183 & 1.185 & 1.187 & 1.236 & 1.371 & 1.387 \\
\hline $\mathrm{Cl}$ & 0.005 & 0.005 & 0.005 & 0.004 & 0.004 & 0.004 & 0.004 & 0.004 & 0.003 & 0.003 & 0.004 & 0.003 \\
\hline $\mathrm{OH}$ & 3.995 & 3.995 & 3.995 & 3.996 & 3.996 & 3.996 & 3.996 & 3.996 & 3.997 & 3.997 & 3.996 & 3.997 \\
\hline$x$ & 0.813 & 0.785 & 0.786 & 0.802 & 0.824 & 0.819 & 0.817 & 0.815 & 0.813 & 0.764 & 0.629 & 0.613 \\
\hline
\end{tabular}

the $\mathrm{H}_{2} \mathrm{O}$ content $(4 \mathrm{OH}+\mathrm{Cl}$ pfu$), \mathrm{Fe}^{3+} / \mathrm{Fe}^{2+}$ ratio and $x$ value were calculated based on the stoichiometry of general formula $\left(\mathrm{Fe}^{2+}{ }_{3-x} \mathrm{Fe}^{3+}{ }_{x}\right)\left(\mathrm{Si}_{2-x} \mathrm{Fe}^{3+}\right)$ $\mathrm{O}_{5}(\mathrm{OH})_{4}$

$n=$ number of point analyses averaged 
Mn is lacking in the studied Chyñava cronstedtite. A very variable content of $\mathrm{Mg}$, from zero to (an exceptional value) 0.14 apfu was observed in synthetic samples of Pignatelli et al. (2013), together with Al, varying from zero to (an exceptional value) $0.28 \mathrm{apfu}$. Obviously $\mathrm{Mg}$ (and $\mathrm{Mn}$ ) partially replaces $\mathrm{Fe}$ in octahedra, and $\mathrm{Al}$ might enter both octahedral and tetrahedral positions.

Only two crystals of other polytypes were found. One of them (labelled 2-2, from the cavity) contains the $3 T$ polytype, belonging to the subfamily A. The crystal is twinned by reticular merohedry of order 3 , with twofold axis (or more general $(2 n-1) \times 60^{\circ}$ rotation) parallel to c as twin operation. This operation exchanges obverse/ reverse settings of the rhombohedral subfamily structure (Ferraris et al. 2008). This type of twinning is typical of the $3 T$ polytype from Nižná Slaná (Hybler et al. 2017). It has been also scarcely observed in the rare $6 T_{2}$ polytype, and in the $3 T+1 M$ mixed crystal from Pohled (Hybler et al. 2016). Images of reciprocal lattice planes of twinned crystals were already presented in these studies. Also worth noting is that Vrba (1886) published drawings of interpenetrating pyramidal cronstedtite crystals from Kutná Hora obviously twinned by this law. The top part of the crystal studied was cleaved out, placed into resin and polished section was prepared. The result of EPMA (Tab. 2) reveals slightly higher content of $\mathrm{Mg}(0.19-0.21 \mathrm{apfu}$, Fig. 4b), than in the prevailing crystals $\left(2 \mathrm{H}_{1}\right.$ and $2 \mathrm{H}_{2}$ polytypes) at the locality.

Another unique crystal (labelled 1-4) produced hhl diffraction pattern of $\mathrm{A}+\mathrm{C}$ subfamilies superimposed. The characteristic reflections of the $1 T$ polytype (subfamily C) are recognizable as dense spots in diffuse streaks produced by the partial stacking disorder. The crystal was cleaved into four fragments labeled 1-4-P, 1-4-T, 1-4-M, 1-4-B, representing the Peak, Top, Medium, and Bottom parts, respectively. These fragments were studied separately in order to reveal eventual changes in the distribution of polytypes within a single crystal. Full experiments were performed and lattice parameters are reported in Tab. 1 .

The diffraction patterns of the apical part contain reflections of the pure $1 T$ polytype (subfamily C), with somewhat diffusely smeared characteristic reflections (Fig. 5a-b). No reflections of the A subfamily are present. In the $h h l$ plane of the top part, reflections of both

Fig. 4 Binary plots of $x$ value (of the ideal formula $\left(\mathrm{Fe}^{2+}{ }_{3-x} \mathrm{Fe}^{3+}{ }_{x}\right)\left(\mathrm{Si}_{2-x} \mathrm{Fe}^{3+}{ }_{x}\right)$ $\mathrm{O}_{5}(\mathrm{OH})_{4}$,) vs. $\mathrm{Cl}(\mathrm{apfu})($ a) and $\mathrm{Mg}$ (apfu) (b) for the studied cronstedtite from Chyňava. 


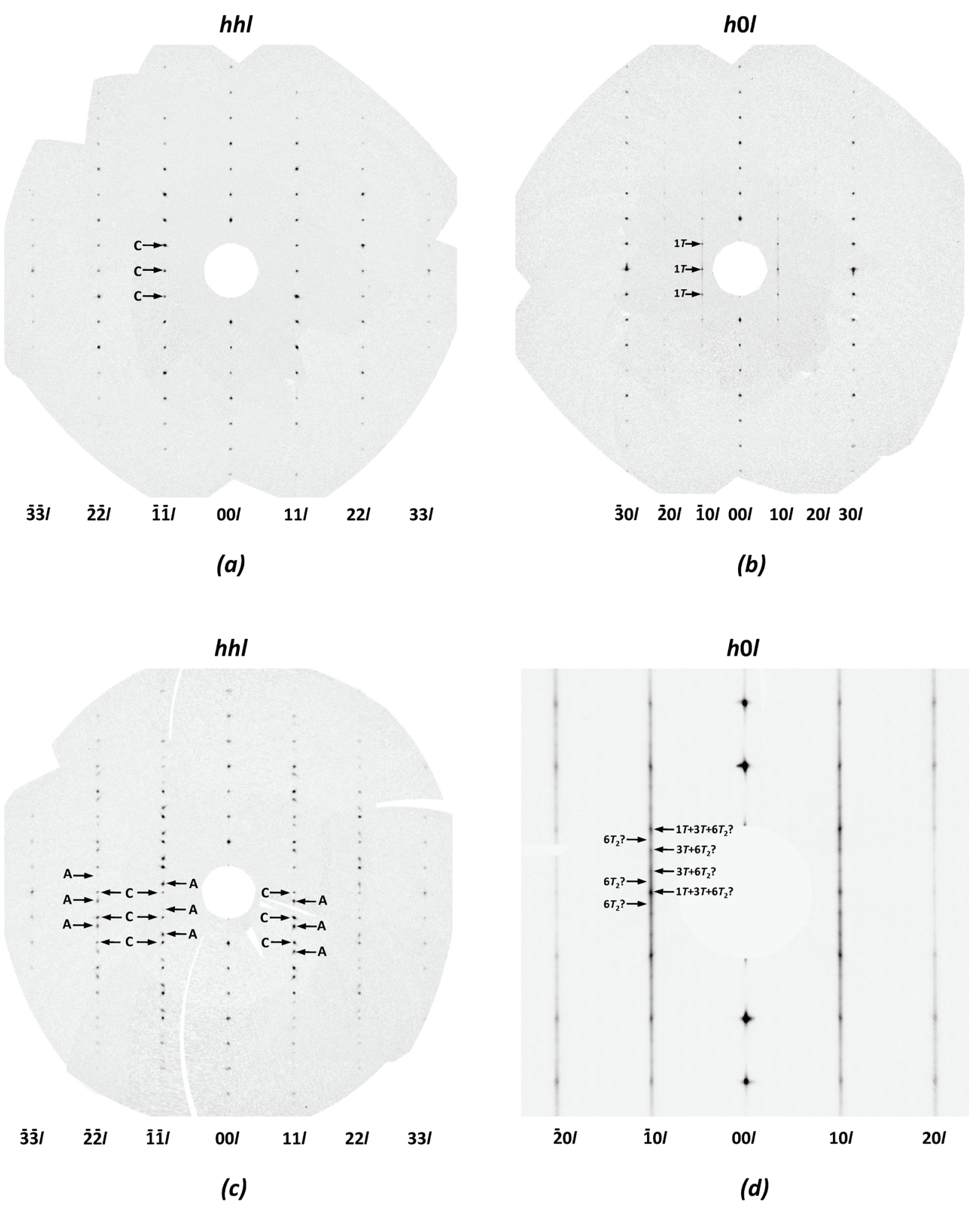

Fig. 5 Reciprocal lattice planes of the mixed crystal of A+C subfamilies, full experiments. a - The peak part of the crystal (1-4-P), hhl plane characteristic of the subfamily $\mathrm{C}$, some of reflections indicated by arrows. No reflections of the subfamily A are present in the image. $\mathbf{b}-$ The apical part of the crystal, $h 0 l$ plane, reflections of the $1 T$ polytype are indicated by arrows. Note diffuse streaks due to partial stacking disorder. $\mathbf{c}-$ The bottom part (1-4-B), full experiment (876 frames), Rigaku Oxford Diffraction SuperNova diffractometer, hhl plane containing A+C subfamily reflections (indicated by arrows). The $\mathrm{C}$ subfamily reflections are at the same levels as $00 l$ ones, while the A subfamily reflections are shifted in vertical direction by $+1 / 3$ or $-1 / 3$ of the periodicity of $00 l$ ones. $\mathbf{d}$ - The bottom part (1-4-B), $h 0 l$ plane, characteristic reflections in diffuse streaks are indicated. While the $1 T$ and $3 T$ polytypes can be relatively well recognized, the presence of the $6 T_{2}$ polytype remains questionable. This image is magnified $2.5 \times$ with respect to previous ones. 
$(\mathrm{A}+\mathrm{C})$ subfamilies are present, in the $h 0 l$ plane there are strong $1 T$ and very weak $3 T$ characteristic reflections in diffuse streaks. The diffraction patterns of the medium part reveal strong $\mathrm{C}$ and very faint $\mathrm{A}$ subfamily reflections, and characteristic $1 T$ reflections in diffuse streaks.

The bottom part was studied using the SuperNova diffractometer (Rigaku Oxford Diffraction), with more intense $\mathrm{X}$-ray source. The diffraction patterns show again presence of both $(\mathrm{A}+\mathrm{C})$ subfamilies (Fig. $5 \mathrm{c})$. In diffuse streaks, the $1 T$ and, less intense, $3 T$ reflections are present. Moreover, very faint reflections revealing sextuple periodicity can be recognized. A possible interpretation might be an accessory of the non-standard polytype $6 T_{2}$ from the subfamily A (Fig. 5d). This polytype was recently described from Pohled (Hybler et al. 2016), where it is relatively abundant. However, because of scarcity of characteristic reflections, presence of this polytype remains uncertain.

The 1-4-T and 1-4-M fragments were placed into the resin, polished sections were prepared and EPMA studies in the WDS mode were performed. These fragments are even more Mg-rich (0.22-0.24 apfu) and Fe-poor ( $x=$ $0.60-0.64$ ) than all other crystals (Tab. 2, Fig. 4b).

Similar mixed crystal $(1 M+1 T$ polytypes of $\mathrm{A}+\mathrm{C}$ subfamilies) has been recognized by the first author in the synthetic material prepared by Pignatelli et al. (2013). Several mixed crystals of $\mathrm{A}+\mathrm{C}$ subfamilies from Lostwithiel, UK, were studied by precession method, HRTEM (High Resolution Transmission Electron Microscopy), and SAED by Kogure et al. (2002). Top parts of conical crystals were built up of the well-ordered $1 T$ polytype, while bottom parts contained disordered domains of A and $\mathrm{C}$ subfamilies. The subfamily A domains were somewhat more $\mathrm{Fe}$ rich, providing thus a brighter contrast in BSE. Another A $+\mathrm{C}$ mixed crystal $(1 M+1 T)$ of an extraterrestrial origin was reported by Müller et al. (1979) in the Cochabamba (CM2) carbonaceous chondrite.

\subsection{General considerations}

In the present occurrence, most specimens are very similar, with dominant $2 H_{1}$ polytype accompanied sometimes by $2 \mathrm{H}_{2}$. Other crystals (twinned $1 T$ polytype and complicated $\mathrm{A}+\mathrm{C}$ subfamily crystal) are rare. Their occurrence might be related to possible local changes of crystallization conditions during the crystal growth. The differences in contents of $\mathrm{Mg}$ seem not be important - a variety of polytypes occur in $\mathrm{Mg}$-free samples from other localities as well. It should be noted that the Chyñava sample is the first known example of $\mathrm{Mg}$-bearing terrestrial cronstedtite without any Mn content.

The crystallization of cronstedtite and formation of polytypes remains still unclear and should be a subject of future research. It seems now probable that presence of substituting elements in polyhedra $(\mathrm{Mg}, \mathrm{Mn}, \mathrm{Al})$ or in anionic positions $(\mathrm{Cl}$ in all recently studied occurrences, $\mathrm{S}$ in Nižná Slaná or meteorites) does not affect the formation of polytypes. Some information about the temperature range of crystallization $\left(60-90^{\circ} \mathrm{C}\right)$ was provided by the experiment of Pignatelli et al. (2013), however, without any pressure control.

Some characteristic properties of cronstedtite assemblages found/examined recently are summarized here:

1) Natural terrestrial cronstedtite always occurs in a very intimate relation with pyrite: embedded, intergrown, on the surface or in a close proximity (few $\mathrm{mm}$ ). This is not true for synthetic or meteoritic cronstedtite, though.

2) In one assemblage, usually one or few type(s) of crystals are dominant, like: $2 \mathrm{H}_{1}\left(+\right.$ sometimes $2 \mathrm{H}_{2}$ ) polytype (this study); $1 T$ (Litošice); $3 T$ polytype, sometimes twinned (Nižná Slaná); $2 \mathrm{H}_{1}+2 \mathrm{H}_{2}, 3 \mathrm{~T}+1 \mathrm{M}$ mixed crystals, 6T (Pohled) (Hybler 1998, Hybler et al. 2016, 2017). In the Pohled assemblage, all three dominant types co-exist in a very small area $\left(\mathrm{few} \mathrm{cm}^{2}\right)$, and there are no significant differences in chemical compositions.

3) It has been confirmed in this and several previous studies that there is certain relation of the Fe content in tetrahedra to the formation of polytypes (or rather subfamilies). The sequence of subfamilies, from $\mathrm{Fe}-$ -poor/Si-rich to Fe-rich/Si-poor is as follows: $\mathrm{C}-\mathrm{A}$ - D, cf. analyses in Hybler et al. (2000, 2002, 2016, 2017) and Kogure et al. (2002).

4) Certain polytypes occur frequently $\left(1 \mathrm{~T}, 3 \mathrm{~T}, 2 \mathrm{H}_{2}, 2 \mathrm{H}_{1}\right)$, while the other ones are rare.

5) Within one assemblage, and within one crystal type, crystals of various degree of stacking disorder can be found.

6) Besides the dominant crystal type(s), sporadic crystals not typical of a given assemblage might occur.

7) Domains of different polytypes, even of different subfamilies (usually $\mathrm{C}+\mathrm{A}$ ) might co-exist in a single crystal. Also the degree of the stacking disorder can change within one crystal.

These facts indicate that the formation of polytypes, twins, mixed crystals, and variation in the degree of disorder probably depend on very small spatial and/or temporal changes in crystallization conditions.

\section{Conclusions}

The study represents a further part of systematic mapping of occurrences of cronstedtite polytypes from localities in Czech and Slovak republics. The cronstedtite polytype $2 H_{1}$ (of the subfamily - Bailey's group D) was found to be the most abundant in the sample from the borehole 
drilled near Chyňava, Czech Republic. No dependence between the chemical composition and the determined polytype of cronstedtite has been observed.

Acknowledgements. The first author $(\mathrm{JH})$ thanks Václav Eigner and Michal Dušek (Institute of Physics, Academy of Sciences of the Czech Republic) for their aid with diffraction experiments. We thank Radek Škoda (Faculty of Science, Masaryk University, Brno) for help with electron-microprobe analytical works. Karel Jurek (Institute of Physics, Academy of Sciences of the Czech Republic) helped to check composition of some crystals in the EDS mode. Valuable comments of Milan Rieder, and the second, anonymous referee helped us to improve the text. We also thank the handling editor František Laufek, and the editor-in-chief Vojtěch Janoušek for their help with preparing the final version of the manuscript. The study was supported by the grant 15-04204S of the Czech Science Foundation to JH and by the Ministry of Culture of the Czech Republic (DKRVO 2017/02; National Museum 00023272) to JS.

\section{References}

Bailey SW (1969) Polytypism of trioctahedral 1:1 layer silicates. Clays Clay Miner 17: 355-371

BaILEY SW (1988) Polytypism of 1:1 layer silicates. In: BAILEY SW (ed) Hydrous Phyllosilicates (Exclusive of Micas). Mineralogical Society of America Reviews in Mineralogy 19, Washington, D.C., 9-27

BARBER DJ (1981) Matrix phyllosilicates and associated minerals in $\mathrm{C} 2 \mathrm{M}$ carbonaceous chondrites. Geochim Cosmochim Acta 45: 945-970

BRowning LB, McSweEn HY JR, Zolensky ME (1996) Correlated alteration effects in CM carbonaceous chondrites. Geochim Cosmochim Acta 60: 2621-2633

BURBINE TH, BURNS RG (1994) Questions concerning the oxidation of the ferrous iron in carbonaceous chondrites. In: Abstracts of the $25^{\text {th }}$ Lunar and Planetary Science Conference, held in Houston, TX, 14-18 March 1994, pp 199-200

Damour MA (1860) Analyse de la cronstedtite, espèce minérale. Ann Chim Phys 58: 99-103 (in French)

Dornberger-SChIFF K, ĎUrovič S (1975a) OD-interpretation of kaolinite-type structure - I: symmetry of kaolinite packets and their stacking possibilities. Clays Clay Miner 23: 219-229

Dornberger-SchifF K, Ďurovič S (1975b) OD-interpretation of kaolinite-type structures - II: the regular polytypes (MDO-polytypes) and their derivation. Clays Clay Miner 23: 231-246

Dyl KA, Manning CE, Young ED (2010) The implication of the cronstedtite in water-rich planetesimals and asteroids. In: Astrobiology Science Conference 2010, League City, Texas, Abstract \#5627

Ďurovič S (1981) OD-Charakter, Polytypie und Identifikation von Schichtsilikaten. Fortschr Mineral 59: 191-226 (in German)

Ďurovič S (1997) Cronstedtite-1 $M$ and coexistence of $1 M$ and $3 T$ polytypes. Ceramics - Silikáty 41: 98-104

DúROVIČ S (2004) Layer stacking in general polytypic structures. In: Prince E (ed) International Tables for Crystallography, Vol. C, Section 9.2.2. $3^{\text {rd }}$ ed., Kluwer, Dordrecht, pp 760-773

Ferraris G, Makovicky E, Merlino S (2008) Crystallography of Modular Materials. Oxford University Press, Oxford, pp 1-370

Fiala F (1951) Diabase and weilburgite rocks of the Lower Ordovician at Chyňava. Sbor Nár Musea v Praze ř B Př́ír Vědy VII B: 1-42

Fiala F, KouŘimskÝ J (1980) Cronstedtite from Chyňava, ČSSR. Sbor Nár Musea v Praze 36 B: 35-42

Geiger CA, Henry DL, Bailey SW, Maj JJ (1983) Crystal structure of cronstedtite- $2 \mathrm{H}_{2}$. Clays Clay Miner 31: 97-108

GoLE MJ (1980a) Low-temperature retrograde minerals in metamorphosed Archean banded iron-formations, Western Australia. Canad Mineral 18: 205-214

GoLE MJ (1980b) Mineralogy and petrology of very-low metamorphic grade Archean banded iron-formations, Weld Range, Western Australia. Amer Miner 65: 8-25

HYBLER J (1998) Polytypism of cronstedtite from Chvaletice and Litošice. Ceramics - Silikáty 42: 130-131

Hybler J, Petříček V, Ďurovič S, SMrČoK L (2000) Refinement of the crystal structure of cronstedtite-1T. Clays Clay Miner 48: 331-338

Hybler J, Petř́íček V, FÁbry J, Ďurovič S (2002) Refinement of the crystal structure of cronstedtite- $2 \mathrm{H}_{2}$. Clays Clay Miner 50: 601-613

Hybler J, Sejkora J, Venclík V (2016) Polytypism of cronstedtite from Pohled, Czech Republic. Eur J Mineral 28: 765-775

Hybler J, Števko M, Sejkora J (2017) Polytypism of cronstedtite from Nižná Slaná, Slovakia. Eur J Mineral 29: 91-99

JANOvSKÝ JV (1875) Zur Kenntnis des Cronstedtits von Př́bram. J Prakt Chem 11: 378-385 (in German)

Kirschbaum K, Martin A, Pinkerton AA (1997) $\lambda / 2$ contamination in charge-coupled-device area-detector data. J Appl Cryst 30: 514-516

Kogure T, Hybler J, Ďurovič S (2001) A HRTEM study of cronstedtite: determination of polytypes and layer polarity in trioctahedral 1:1 phyllosilicates. Clays Clay Miner 49: 310-317

Kogure T, Hybler J, Yoshida H (2002) Coexistence of two polytypic groups in cronstedtite from Lostwithiel, England. Clays Clay Miner 50: 504-513 
Lauretta DS, Hua X, Buseck PR (2000) Mineralogy of fine-grained rims in the ALH 81002 CM chondrite. Geochim Cosmochim Acta 64: 3263-3273

López García Ja, Manteca Ji, Prieto, AC, Calvo B (1992) The first occurrence of cronstedtite in Spain. Structural characterisation. Bol Soc Esp Mineral 15-1: 21-25 (in Spanish)

MiKLoš D (1975) Symmetry and Polytypism of Trioctahedral Kaolin-Type Minerals. Unpublished Ph.D. thesis, Institute of Inorganic Chemistry, Slovak Academy of Sciences, Bratislava, pp 1-144 (in Slovak)

MĚSKa G, Prantl F, Fiala F (1945) Questionnaire of drilling - Chyňava. Geologische Anstalt für Böhmen und Mähren. (Stored in Czech Gelogical Survey-GEOFOND Prague, Surv. Report V011162, in Czech and German)

Müller WF, KuRat G, Kracher A (1979) Chemical and crystallographical study of cronstedtite in the matrix of the Cochabamba (CM2) carbonaceous chondrite. Tschermaks Mineral Petrogr Mitt 26: 293-304

NovÁK F, Hoffman V (1956) Occurrence of new minerals in the ore district of the northern part of the Iron Mts. Rozpr ČSAV Ř Mat Přír Věd 66: 31-48 (in Czech with an English abstract)

Novák F, JANSA J (1965) Paragenesis of minerals with helvine from the Chvaletice deposit. Čas Mineral Geol 10: 75-79 (in Czech)

Novák F, VtěLenskÝ J, Losert J, Kupka F, Valcha Z (1957) Orthochamosite from ore veins in Kaňk near Kutná Hora, a new specific mineral. In: Sborník k osmdesátinám akademika F. Slavíka. Naklatelství ČSAV, Prague, pp 315-343 (in Czech)

Pignatelli I, Mugnaioli E, Hybler J, Mosser-Ruck R, Cathelineau M, Michau N (2013) A multi-technique characterisation of cronstedtite synthetized by iron-clay interaction in a step by step cooling procedure. Clays Clay Miner 61: 277-289
Pouchou JL, Pichoir F (1985) “PAP” ( $\varphi \rho Z)$ procedure for improved quantitative microanalysis. In: ARMSTRONG JT (ed) Microbeam Analysis. San Francisco Press, San Francisco, pp 104-106

Rigaku Oxford Diffraction (2015) CrysAlis Pro, Data collection and data reduction GUI. Version 171.38.41q

Schulte M, Schock E (2004) Coupled organic synthesis and mineral alteration on the meteorite parent bodies. Meteorit Planet Sci 39: 1577-1590

SteADMAN R (1964) The structure of trioctahedral kaolintype silicates. Acta Cryst 17: 924-927

SteadMan R, NutTall PM (1964) Further polymorphism in cronstedtite. Acta Cryst 17: 404-406

Steinmann JJ (1820) Chemische Untersuchung des Cronstedtit's, eines neuen Fossils von Př́bram in Böhmen. Gottlieb Haase, Prague, pp 1-47 (in German)

Steinmann JJ (1821) Chemische Untersuchung des Cronstedtit's, eines neuen Fossils von Pribram in Böhmen. J Chem Phys 32: 69-100 (in German)

Varček C, Vasconselos JM, Petrová R, Fejdi P (1990) Cronstedtite $\left(\mathrm{Fe}^{2+}{ }_{2} \mathrm{Fe}^{3+}\right)\left(\mathrm{SiFe}^{3+} \mathrm{O}_{5}\right)(\mathrm{OH})_{4}$, from Klement vein, Rožňava. Miner Slov 22: 565-567 (in Slovak)

VRBA K (1886) Vorläufige Notiz über den Cronstedtit von Kuttenberg. Sitz-Ber Kgl Böhm Gessel Wiss 3: 13-19 (in German)

Wahle MW, Bujnowski TJ, Guggenheim S, Kogure T (2010) Guidottiite, the Mn-analogue of cronstedtite: a new serpentine-group mineral from South Africa. Clays Clay Miner 58: 364-376

Weiss Z, KuŽVART M (2005) Clay Minerals, Their Nanostructure and Use. Karolinum, Charles University publishing house, Prague, pp 1-281 (in Czech)

ZeGa TJ, BUSECK PR (2003) Fine-grained-rim mineralogy of the Cold Bokkeveld CM chondrite. Geochim Cosmochim Acta 67: 1711-1721 